\title{
Ozone Generation of Electric Field Induction at Sharp Edges Electrodes: Simulation and Experimental Study
}

\author{
Syarifa Fitria*, Rizda Fitri Kurnia, Zainuddin Nawawi, Dwirina Yuniarti, Tresna Dewi, Zolkafle \\ Buntat, Muhammad Abu Bakar Sidik
}

Jl. Raya Palembang - Prabumulih Km. 32 Indralaya, OI, Sumatera Selatan 30662

Received 5 March 2021; Accepted 31 March 2021

\begin{abstract}
This paper presents the effects of electric field induction using electrodes perforated shape and hexagonal shape for ozone generation which are experimentally investigated and simulated as well. Dielectric barrier discharge reactors using a planar configuration with ac power supply and soda-lime glass as the dielectric material. The effects of the electric field induction at sharp edges make electron avalanches around sharp edges during the discharge process, a high ozone concentration is obtained. Ansys Software 18.2 was carried out to conduct finite element analysis. The increasing electric field and current direction vector confirm the increasing ozone concentration by using hexagonal shape as $30,6 \%$ higher than perforated shape.
\end{abstract}

Keywords: ozone concentration; hexagonal shape; perforated shape; finite element analysis;

\section{Introduction}

Dielectric barrier discharge (DBD) can also be called a silent discharge formed by two electrodes mounted in parallel where either electrode or both electrodes are coated with a dielectric material separated by a dielectric barrier. Dielectric material is used to limit current, charge and power in micro discharge. These purpose to distribute micro discharge throughout the surface. The air gap between the electrode and the dielectric material has a homogeneous discharge volume along the reaction chamber thus that the resulting temperature does not require a cooling system. DBD systems are used under atmospheric pressure consequently known to be a good and cost-effective ozone production method [1]-[8].

Dielectric barrier discharge uses a dielectric layer made of glass soda lime, quartz, ceramic or polymer materials placed between the electrodes. Generally dielectric barrier discharges operate at atmospheric pressures ranging from 0.1 to $1 \mathrm{~atm}$, with voltages of $1-100 \mathrm{kV}$ and frequencies from $\mathrm{Hz}$ to $\mathrm{MHz}$ [8]-[9]. Dielectric barrier discharge can produce ultraviolet light, ozone and hydroxyl radicals [10], [11]. One of the popular research in DBD system is ozone production. Ozone is strong oxidizing agents that doesn't have byproduct in the environment. Many applications that have utilized ozone include sterilization, water purification, air purification, food preservation and etc. [12]- [16]. DBD has been continued to be developed to get optimum ozone production. DBD in ozone production is affected by breakdown voltage, gas, pressure, electrode material and electrode geometry [17]. Optimum air gap can be obtained by designing the dielectric barrier discharge reactor as well to get the maximum output of ozone concentration [18]. Based on previous research using perforated holes, has been carried out

*E-mail address: fitria_syarifa@yahoo.com

ISSN: 1791-2377 @ 2021 School of Science, IHU. All rights reserved. doi:10.25103/jestr.141.05
[19]-[20]. This paper discusses comparison of different holes shape electrodes using simulation and experimental. In this research, different two holes shapes are used, the first is perforated holes shapes, and the other is hexagonal holes shapes. Simulation and experimental of both holes shapes are compared to get the optimum ozone production by using DBD method.

\section{Reduction - Oxidation Model}

Ozone formation will have a high electron energy between 1$10 \mathrm{eV}$ produced by the DBD method [4]. The basic principles of ozone formation reactions are as follows:

$\mathrm{e}+\mathrm{O}_{2} \rightarrow 2 \mathrm{O}+\mathrm{e}$

$\mathrm{O}+\mathrm{O}_{2} \rightarrow \mathrm{O}_{3}$

$\mathrm{O}+\mathrm{O}_{3} \rightarrow \mathrm{O}_{2}+\mathrm{O}_{2}$

$\mathrm{e}+\mathrm{O}_{3} \rightarrow \mathrm{O}_{2}+\mathrm{O}$

Based on reaction formulae $1-4$, it showed that ozone is able to react quickly and return to oxygen due to the ozone decomposition process.

\section{Simulation Setup}

The geometry used in this simulation and experiment represents solid model of electrodes as showed in Fig.1 and Fig. 2 which will be analyzed for its electrical characteristics.

This simulation using Ansys Software Program 18.2. For the step, makes a grid to describe the geometry in which electric field is applied. This simulation uses a mesh size set at $0.5 \mathrm{~mm}$ to obtain high accuracy. The resulting electric field distributions for perforated and hexagonal are presented in Fig. 4 and Fig. 5. 


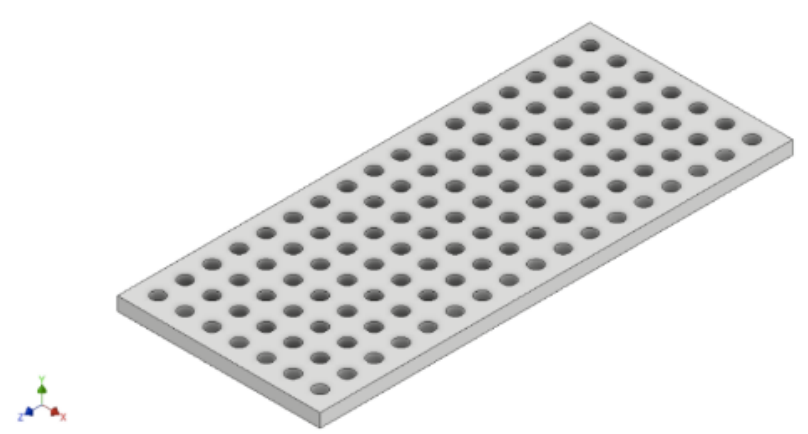

Fig.1. Geometry perforated shape

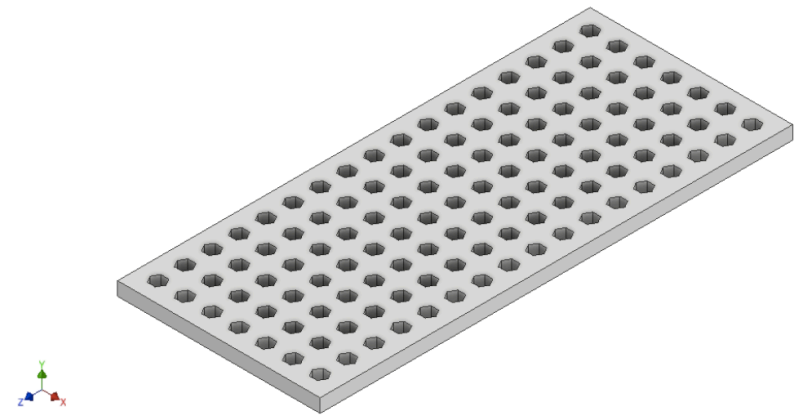

Fig.2. Geometry hexagonal shape

The Finite Element Analysis (FEA) theory is used in simulations to get structural analysis, conduction to electromagnetic [21]. General electromagnetic equations in the form of differential integrals are shown through eq. 5-6 below:

Maxwell - Ampere equation:

$\oint \vec{H}^{\circ} d \vec{l}=\int_{S}\left(J_{c}+\frac{\partial \vec{D}}{\partial t}\right) \circ d \vec{S}$

Faraday equation:

$\oint \vec{E}^{\circ} d \vec{l}=\int_{S}\left(-\frac{\partial \vec{B}}{\partial T}\right) \circ d \vec{S}$

Where $\mathrm{E}(\mathrm{N} / \mathrm{C})$ is electric field intensity vector, $\mathrm{H}$ were used to Magnetic field strength and direction $(\mathrm{A} / \mathrm{m})$, Current density $(\mathrm{A} / \mathrm{m})$ indicated by $\mathrm{J}$.

Two equation sets were used to describe the evolution of a micro discharge [22]. The continuity equations for the charged species $n_{i}$ (electrons, positive and negative ions) with source and sink terms $S_{i}$ (describing ionization and attachment) can be written as:

$\frac{\partial n_{i}}{\partial_{t}}+\nabla .\left(v n_{i}+D_{i} \nabla v n_{i}\right)=S_{i}$

where $v=\mu \mathrm{E}$ is the drift velocity, defined as mobility $\mu$ times electric field strength $\mathrm{E}$ and $D i$ is the diffusion coefficient. E again is defined as the gradient of the potential $\varphi, \mathrm{E}=-\nabla \varphi$. It is related to the charge density $\rho$ by Poisson's equation:

$\nabla^{2} \varphi=-\frac{\rho}{\varepsilon}$

\section{Experimental Setup}

A schematic diagram of the experimental setup is shown in Fig.3. All experiments were performed at atmospheric pressure. The ozone concentration was generated using ozone analyzer BMT 964-bt.

The input gas using oxygen with flow rate $0,1 \mathrm{~L} / \mathrm{m}$. The oxygen in the ozone chamber was discharged by high voltage probe (Tektronix P6015A, 1000:1,3.0 pF, $100 \mathrm{M} \Omega$ ) and voltage waveform was recorded using Picoscope 3206B (200 $\mathrm{MHz}, 500 \mathrm{MS} / \mathrm{s}$ ). The input voltage from $1 \mathrm{kV}$ to $7 \mathrm{kV}$ to the reactor chamber DBD. Ozone concentration was generated using ozone analyzer bmt 964-bt. The rest being exhausted to the atmosphere. The experimental arrangement used to compare the electrode holes shape between perforated and hexagonal. The gap spacing using $1 \mathrm{~mm}$.

\section{Dielectric Barrier Discharge Model}

The main principle in the use of these electrodes is to produce high ozone concentrations due to sharp edges thus produce high electric fields. These electrodes are connected with copper wire sticked together using conductive silver as a conduit of electric current into the electrodes (Fig.4). Electrodes that have been connected with copper wire are placed into the DBD chamber and then placed glass at one side of the electrode. The gap between dielectric material and electrodes is $1 \mathrm{~mm}$ apart.

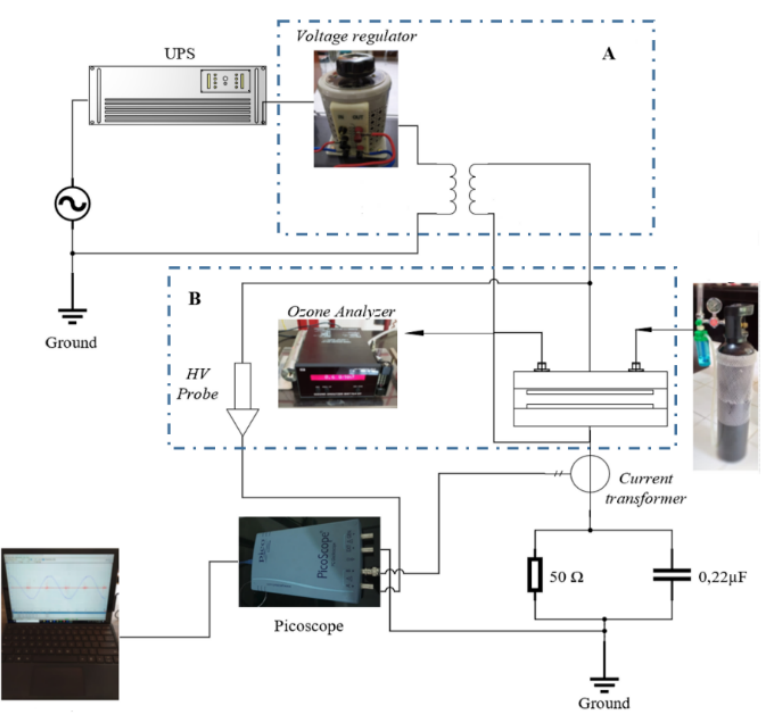

Fig 3. Experimental setup

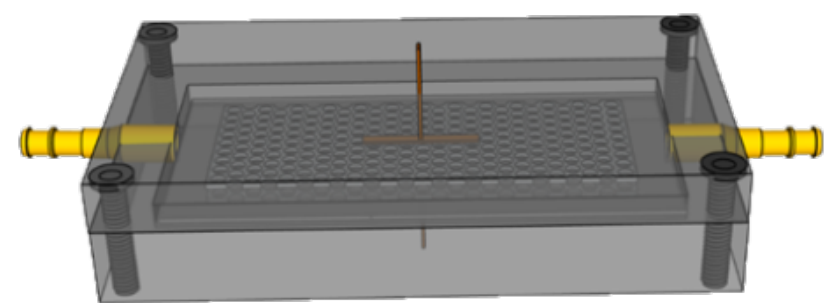

Fig. 4. Dielectric Barrier Discharge Model [20]

\section{Results and Discussion}

\section{Simulation Results and Discussion}

Electric field computations for both holes shape were carried out using simulation software (Ansys 18.2) to simulate electromagnetic fields and current density. As shown in Fig.5 - Fig. 8 , generated electric field are related to eq. $(5-8)$.

The simulation is carried out using two holes shape models, perforated and hexagonal shapes. Simulations are carried out to determine the pattern of electric field 
distribution and current density in two different holes shape models.

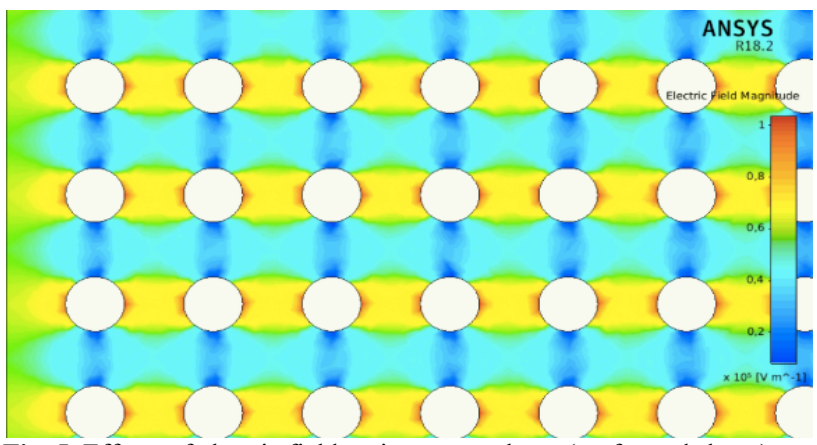

Fig. 5. Effects of electric field on increase voltage (perforated shape)

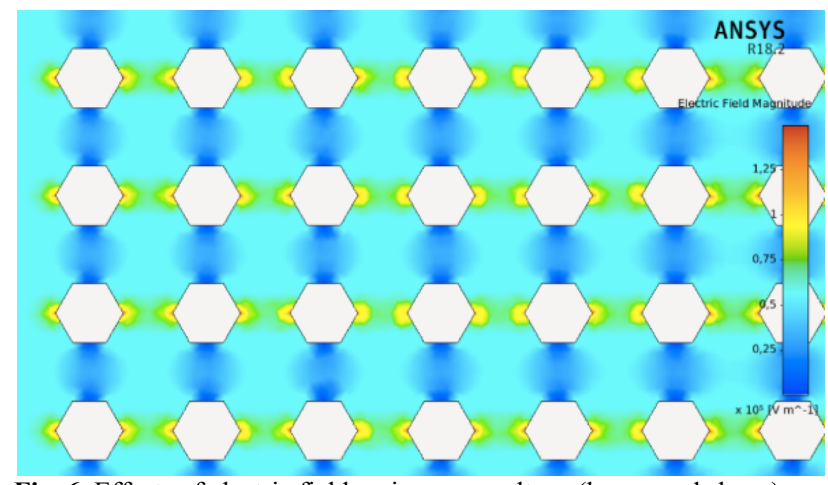

Fig. 6. Effects of electric field on increase voltage (hexagonal shape)

The distribution pattern of the electric field is concentrated at the edges of the holes and has a high value at the perpendicular to the potential difference and has a relatively low value in the direction of the potential difference. Fig.5 and Fig. 6 show the comparison of the electric field between perforated shape with hexagonal shape, it appears that the electric field in hexagonal shape is $30.6 \%$ higher when compared to perforated shape, but perforated shape has an electric field distribution pattern that tends to be more evenly distributed than hexagonal shape. High electric field strength makes the movement of electrons faster which forms electrons avalanche on the electrode surface resulting in high ozone concentrations

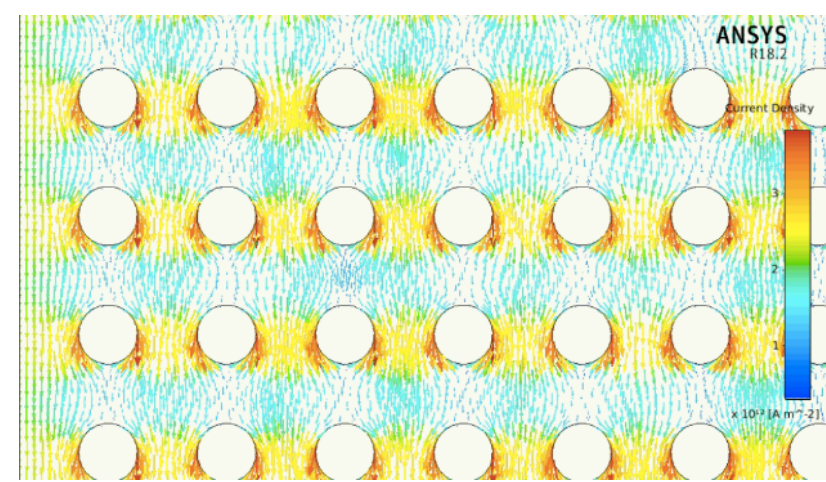

Fig. 7. Effects of current density on increase voltage (perforated shape)

Increased voltage results in higher current density. The shape of the holes also influences the pattern of current density distribution significantly. In Fig. 7 and Fig. 8, there are increasing current density of the angular part of the holes and the highest part is contacted with the tangent of the holes. The hexagonal shape appears to have a maximum current density of $30.6 \%$ higher compared to perforated shape, but the perforated shape has more even distribution pattern of current densities.

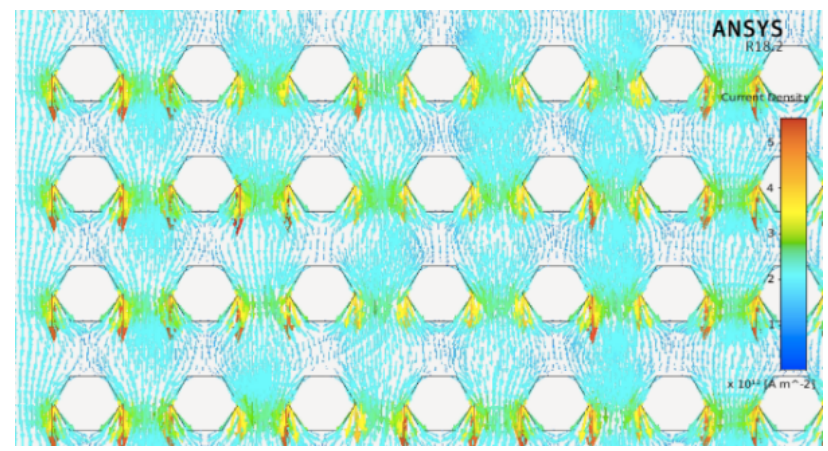

Fig. 8. Effects of current density on increase voltage (hexagonal shape)

From the results gathered in Fig. 9 and Fig. 10, there are voltage increased impact on current density and electric field with different holes shape. The results obtained also proved that main effect of the electric field is increasing the ozone concentration with different holes shape. When voltage increases, electric field and current density are increasing as well. These results make an impact for ozone concentration that already known when voltage is increasing, ozone concentration will be increased as well [23]-[24].

Based on Fig. 9, the electric field from $4 \mathrm{kV}$ to $7 \mathrm{kV}$ has been increased by $43 \%$ for perforated shape and $42,9 \%$ for hexagonal shapes that make hexagonal-shaped electrodes induce higher electric field linearly than the perforated one. While the current density of hexagonal shaped electrodes was also higher compare to perforated ones (Fig.10).

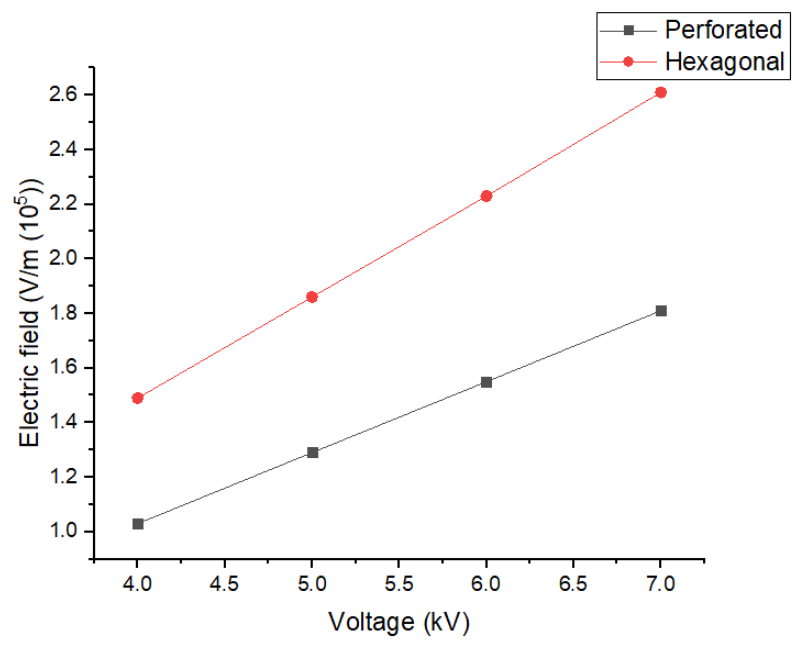

Fig. 9. Effects of electric field on increase voltage

\section{Experimental Results and Discussion}

Comparison using electrodes with two different holes shape, specifically perforated and hexagonal shape with $2 \mathrm{~mm}$ diameter. Soda lime glass use as dielectric material with thickness $1 \mathrm{~mm}$. The results of ozone concentration obtained by electrodes in a hexagonal and perforated shape at $7 \mathrm{kV}$.

The results of increase ozone concentration in Table 1 shows the hexagonal-shaped is $72 \%$ higher ozone concentration when compared with the perforated-shaped. This result is influenced by the number of dense holes, the effects of sharp and small edges on the surface of the electrodes thus as to produce high electric field strengths and amount of charge. The amount of charge generated and 
separated influences the increase in ozone concentration. The electric charge is formed when the electric field accelerates the electrons thus the electrons have enough energy to ionize the oxygen molecules in the reactor [25].

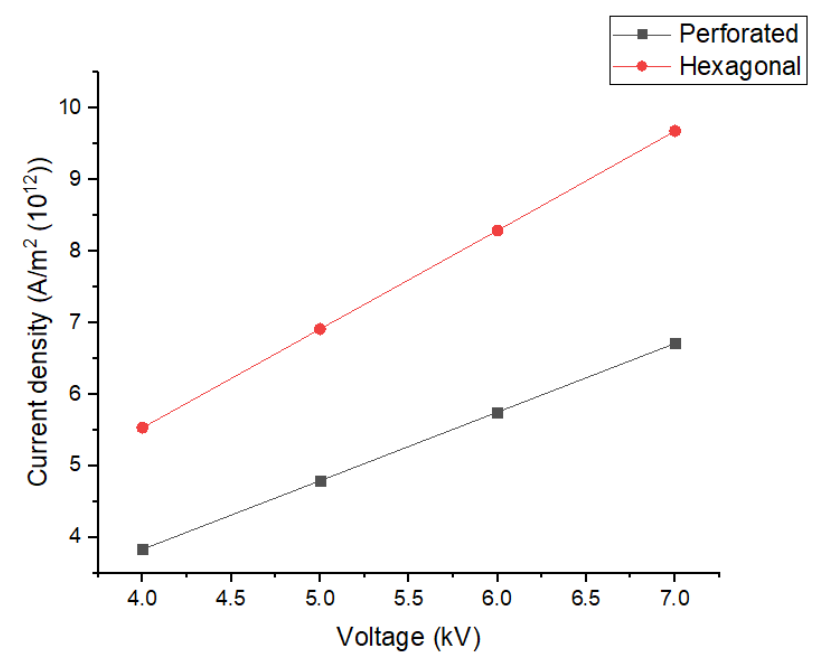

Fig. 10. Effects of current density on increase voltage

Table 1. Comparison of ozone concentrations in different holes-shaped electrodes with hexagonal and perforated shape

\begin{tabular}{lll}
\hline Parameter & \multicolumn{2}{l}{$\begin{array}{l}\text { Different } \\
\text { Electrodes with soda lime glass } \\
\text { dielectric material }\end{array}$} \\
\cline { 2 - 3 } & Hexagonal & Perforated \\
\hline Open area $(\%)^{* *}$ & 93,5 & 80,74 \\
Capacitance $(\mathrm{pF}) * *$ & 1,36 & 3,17 \\
$\begin{array}{l}\text { Ozone concentration } \\
(\mathrm{ppm})\end{array}$ & 2185,31 & 611,8 \\
\hline
\end{tabular}

In the overall voltage variation, the difference shape of the holes results in a change the distribution pattern of electric field. The greater voltage gains greater electric field. The distribution pattern of the electric field is concentrated at the edge of the holes and has a high value at the perpendicular to the potential difference and has a relatively low value in the direction of the potential difference.

From the results known through Fig.5 - Fig.8 shows the effect of voltage on the current density and electric field with different holes shape. The results obtained also prove the impact of increasing electric field on the ozone concentration with different holes shape. When an electric field increases, the concentration of ozone produced is higher. These results are in accordance with previous studies [19] on perforated aluminum using simulation (Ansoft-Maxwell 2D) with the Electric Field Strength (EFS) method states that there is an influence of the electric field on sharp edges. Other results also show the effect of geometric shape and sharp edges on ozone concentration [26].

\section{Conclusion}

In this paper, the effect of electric field and current density of DBD reactor were studied, and effects on ozone concentration re compared. The experimental investigation was performed by used high voltage and the simulation was confirmed the effects of different hole shapes. Ozone concentration is higher when using hexagonal holes shape than perforated holes due to the sharp edges. The electric field has induced sharp edges that make electron avalanches moving faster thus dissociation and ionization with molecule oxygen and atom $\mathrm{O}$ hence recombination form ozone. Consequently, an increase in the electric field might increase the concentration of ozone.

This is an Open Access article distributed under the terms of the Creative Commons Attribution License.

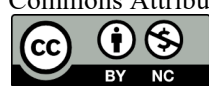

\section{References}

1. U. Kogelschatz, B. Eliasson, and W. Egli, "Dielectric-Barrier Discharges . Principle and Applications.," J. Phys. IV, vol. 07, no. C4, pp. 47-66, 1997.

2. X. Xu, "Dielectric barrier discharge - Properties and applications," Thin Solid Films, vol. 390, no. 1-2, pp. 237-242, 2001.

3. A. Bogaerts, E. Neyts, R. Gijbels, and J. van der Mullen, "Gas Discharge Plasma and Their Applicatioms," Spectrochim. Acta Part B At. Spectrosc., vol. 57, no. 4, pp. 609-658, 2002.

4. Z. Fang, Y. Qiu, Y. Sun, H. Wang, and K. Edmund, "Experimental study on discharge characteristics and ozone generation of dielectric barrier discharge in a cylinder-cylinder reactor and a wire-cylinder reactor," J. Electrostat., vol. 66, no. 7-8, pp. 421-426, 2008.

5. M. Moreau, N. Orange, and M. G. J. Feuilloley, "Non-thermal plasma technologies: New tools for bio-decontamination," Biotechnology Advances, vol. 26, no. 6. pp. 610-617, Nov-2008.

6. A. Yehia, "Assessment of ozone generation in dry air fed silent discharge reactors," vol. 023503, no. November 2011, pp. 1-10, 2012.

7. M. H. Kim et al., "Efficient generation of ozone in arrays of microchannel plasmas," J. Phys. D. Appl. Phys., vol. 46, no. 30, 2013.

8. M. Kogoma and S. Okazaki, "Raising of ozone formation efficiency in a homogeneous glow discharge plasma at atmospheric pressure," J. Phys D Appl. Phys., vol. 27, pp. 1985-1987, 1994.

9. H. Conrads and M. Schmidt, "Plasma generation and plasma sources," Plasma Sources Sci. Technol., vol. 9, no. 4, pp. 441-454, 2000 .
10. B. Pashaie, S. K. Dhali, and F. I. Honea, "Electrical characteristics of a coaxial dielectric barrier discharge," J. Phys. D. Appl. Phys., vol. 27, no. 10, pp. 2107-2110, 1994.

11. J. Xue, L. Chen, and H. Wang, "Degradation mechanism of Alizarin Red in hybrid gas-liquid phase dielectric barrier discharge plasmas: Experimental and theoretical examination," Chem. Eng. J., vol. 138, no. $1-3$, pp. $120-127,2008$.

12. M. A. Khadre, A. E. Yousef, and J.-G. Kim, "Microbiological Aspects of Ozone Applications in Food: A Review," J. Food Sci., vol. 66, no. 9, pp. 1242-1252, 2001.

13. M. B. Habibi Najafi and M. H. Haddad Khodaparast, "Efficacy of ozone to reduce microbial populations in date fruits," Food Control, vol. 20, no. 1, pp. 27-30, 2009.

14. J. G. Kim, A. E. Yousef, and S. Dave, "Application of ozone for enhancing the microbiological safety and quality of foods: a review.,"J. Food Prot., vol. 62, no. 9, pp. 1071-1087, 1999.

15. Ł. Jurczyk, J. Koc-Jurczyk, and M. Balawejder, "Quantitative dynamics of chosen bacteria phylla in wastewater treatment plants excess sludge after ozone treatment," J. Ecol. Eng., vol. 20, no. 3, pp. 204-213, 2019.

16. H. Claus, "Ozone Generation by Ultraviolet Lamps," Photochem. Photobiol., pp. 1-6, 2021.

17. H. H. Murbat and F. A. Khudair, "Generation of uniform atmospheric pressure air glow plasma by dielectric barrier discharge with glass as a dielectric," vol. 3, no. 11, pp. 125-131, 2014.

18. K. Kostov and R. Honda, "Characteristics of dielectric barrier discharge reactor for material treatment," Brazilian J. ..., vol. 1, no. 
Syarifa Fitria, Rizda Fitri Kurnia, Zainuddin Nawawi, Dwirina Yuniarti, Tresna Dewi, Zolkafle Buntat, Muhammad Abu Bakar Sidik / Journal of Engineering Science and Technology Review 14 (1) (2021) 56 - 60

3, pp. 322-325, 2009.

19. Z. Buntat, "Generation of a Homogeneous Glow Discharge Using Perforated Aluminium Electrode," pp. 10-15, 2017.

20. S. Fitria, M. A. B. Sidik, M. I. Jambak, D. Yuniarti, and R. F. Kurnia, "The Effects of Different Electrode Holes on Ozone Generation," 2019.

21. S. Zklfk et al., "MODELING OF SINGLE-FILLET LAP JOINT IN SOLIDWORKS SIMULATION,” J. Appl. Eng. Sci., 2019.

22. U. Kogelschatz, "Dielectric Barrier Discharge: Their History, Discharge Physic, and Industrial Applications," Plasma Chem. Plasma Process., vol. 23, p. 1, 2003.

23. Z. Buntat et al., "Generation of a Homogeneous Glow Discharge: A Comparative Study between the Use of Fine Wire Mesh and
Perforated Aluminium Electrodes," Appl. Phys. Res., vol. 3, no. 1, pp. 15-28, 2011.

24. T. Fujishima, "Ozone generation characteristic by different divided outer electrodes of screw electrode ozonizer," J. Int. Counc. Electr. Eng., vol. 8, no. 1, pp. 99-103, 2018.

25. E. A. Muravyova, A. V Bondarev, R. S. Mangina, C. L. Enloe, and G. I. Font, "Power consumption analysis DBD plasma ozone generator Power consumption analysis DBD plasma ozone generator," 2016.

26. E. Gnapowski, "Effect of Mesh Electrodes Geometry on the Ozone Concentration in the Presence of Micanite Dielectric," $A d v$. Sci. Technol. Res. J., vol. 12, no. 4, pp. 76-80, 2018. 